Nol ecul ar i nvestigations of the brai $n$ of hi gher nammal s usi ng gyrencephal i c carni vore ferrets

\begin{tabular}{|l|l|}
\hline 著者 & Kawasaki H r oshi \\
\hline $\begin{array}{l}\text { j our nal or } \\
\text { publ i cat i on t i t l e }\end{array}$ & Neur osci ence Resear ch \\
\hline vol une & 86 \\
\hline page range & $59-65$ \\
\hline year & 2014 09-01 \\
\hline URL & ht t p: //hdl . handl e. net /2297/40589 \\
\hline
\end{tabular}




\section{Molecular investigations of the brain of higher mammals using gyrencephalic carnivore ferrets}

Hiroshi Kawasaki

Graduate School of Medical Sciences, Kanazawa University, Ishikawa 920-8640, Japan

Brain/Liver Interface Medicine Research Center, Kanazawa University, Ishikawa 920-8640, Japan

Correspondence to:

Hiroshi Kawasaki, MD, PhD

Graduate School of Medical Sciences

Kanazawa University

Takara-machi 13-1, Kanazawa, Ishikawa 920-8640, Japan

Tel: +81-76-265-2363, Fax: +81-76-234-4274

E-mail address: hiroshi-kawasaki@umin.ac.jp 


\begin{abstract}
The brains of mammals such as carnivores and primates contain developed structures not found in the brains of mice. Uncovering the physiological importance, developmental mechanisms and evolution of these structures using carnivores and primates would greatly contribute to our understanding of the human brain and its diseases. Although the anatomical and physiological properties of the brains of carnivores and primates have been intensively examined, molecular investigations are still limited. Recently, genetic techniques that can be applied to carnivores and primates have been explored, and molecules whose expression patterns correspond to these structures were reported. Furthermore, to investigate the functional importance of these molecules, a rapid and efficient genetic manipulation method was established by applying in utero electroporation to gyrencephalic carnivore ferrets. In this article, I review recent advances in molecular investigations of the brains of carnivores and primates, mainly focusing on ferrets (Mustela putorius furo).
\end{abstract}

Keywords: ferret, parallel visual pathways, gyrus, OSVZ, in utero electroporation 


\section{Introduction}

Recently, carnivores and primates have attracted more attention from neuroscience researchers than previously because molecular investigations of the brain using these animals are becoming feasible. The brains of carnivores and primates contain developed brain structures that mice do not seem to have. These structures include ocular dominance columns (ODC) in the visual cortex, the magnocellular (M) and parvocellular $(\mathrm{P})$ pathways in the visual system, and the gyrus and outer subventricular zone (OSVZ) of the cerebral cortex. Uncovering the physiological importance, developmental mechanisms and evolution of these structures using carnivores and primates would lead to our understanding of the human brain and its diseases, which are often difficult to investigate using mice. Although the anatomical and physiological properties have been intensively examined, molecular investigations of the formation, function, pathophysiology and evolution of these structures are still limited. This is not only because these structures are only poorly developed in mice, which are most commonly used for molecular investigations of the brain, but also because genetic methods that can be applied to carnivores and primates were poorly available until recently.

To overcome these limitations, genetic techniques that can be applied to carnivores and primates have been explored. Pioneering research projects have reported successful application of virus vectors to make transgenic monkeys and marmosets (Chan et al., 2001; Lois et al., 2002; Sasaki et al., 2009). The injection of a lentiviral vector into marmoset embryos resulted in transgenic marmosets that expressed the transgene in several organs (Sasaki et al., 2009). Notably, germ-line transmission of the transgene was observed, and transgenic offspring developed normally (Sasaki et al., 
2009). Although the creation of transgenic marmosets provides a new animal model for human disease (Okano et al., 2012), making transgenic animals takes time and effort, and requires special animal facilities. Because it was desirable to establish a rapid and simple genetic manipulation method for carnivores and primates, several groups reported post-natal electroporation protocols for ferrets to express transgenes into the retinal and superficial cortical neurons (Borrell, 2010; Huberman et al., 2005). To achieve transgenic expression in most layers of the cerebral cortex in ferrets, we successfully applied in utero electroporation to ferrets (Mustela putorius furo) as discussed below (Kawasaki et al., 2012; Kawasaki et al., 2013). Combining the use of transgenic primates and the genetic manipulation of ferrets would greatly facilitate our understanding of the brain of higher mammals. In this article, I review recent advances in molecular investigations of the brains of higher mammals, mainly focusing on ferrets.

\section{The ferret as a model animal for investigating the cerebral cortex}

The ferret, like the weasel, badger and skunk, belongs to Mustelidae, which is a family of carnivorous mammals. They have an average length of about $50 \mathrm{~cm}$ and weight of about 1-2 kg. Ferrets have a long history as animal model subjects because they have developed brain structures that mice do not have. One of the most prominent features of the ferret brain is the formation of folds in the cerebral cortex (Figure 1). Humans, monkeys and ferrets have gyrencephalic brains (i.e. brains with a folded cerebral cortex), while the brains of rodents are often lissencephalic (i.e. lacking cortical convolutions). Although the mechanisms underlying the formation of the cortical gyrus still remain unclear, it was proposed that the increased number of cortical neurons led to expansion and folding of the cerebral cortex during evolution. It is therefore important to uncover 
the mechanisms regulating the differentiation and proliferation of neural progenitors in the cerebral cortex during development (Borrell and Reillo, 2012; Dehay and Kennedy, 2007; Fietz and Huttner, 2011; Hevner and Haydar, 2012; Lui et al., 2011; Molnar and Clowry, 2012; Rakic, 2009).

Cortical neurons arise from radial glial cells (RG cells, also known as apical progenitors/apical RG cells/ventricular RG cells), the epithelial stem cells that line the cerebral ventricles and extend apical fibers and basal fibers (Malatesta et al., 2000; Miyata et al., 2001; Noctor et al., 2001). RG cells in the ventricular zone (VZ) undergo multiple rounds of asymmetric divisions and generate intermediate progenitor cells (IP cells/basal progenitors) that migrate into the subventricular zone (SVZ) and further proliferate to increase neuronal number (Haubensak et al., 2004; Noctor et al., 2004). Corticogenesis in carnivores and primates is distinguished by the appearance of the large SVZ that has an inner region (ISVZ) and an outer region (OSVZ), often split by a thin layer of fibers, called the inner fiber layer (IFL) (Smart et al., 2002; Zecevic et al., 2005). Recent studies identified a novel class of progenitor cells found in the OSVZ, termed OSVZ radial glial cells (oRG cells, also known as outer RG cells/basal RG cells/intermediate RG cells/translocating RG cells) (Fietz et al., 2010; Hansen et al., 2010; Reillo et al., 2011). Unlike RG cells in the VZ, oRG cells are unipolar, with a basal fiber that ascends toward the pia without an apical fiber that descends toward the ventricle. Because a major underlying cause of the expansion and gyrification of the cerebral cortex could be the increase in population size of neural progenitors in the OSVZ, a specialized germinal zone characteristic of higher mammals, it is important to investigate the mechanisms underlying the proliferation and differentiation of neural progenitors in the OSVZ. The ferret is a good option for investigating such mechanisms, 
given that genetic manipulation using ferrets has become feasible (Borrell, 2010; Kawasaki et al., 2012; Kawasaki et al., 2013; Nonaka-Kinoshita et al., 2013; Pilz et al., 2013; Reillo et al., 2011). Recent studies reported genes expressed in the VZ and SVZ of mice and in various regions of the cerebral cortex in monkeys (Ayoub et al., 2011; Bernard et al., 2012). Manipulating these genes in ferrets would potentially uncover the mechanisms underlying the formation of the gyrus and the OSVZ in the cerebral cortex. In addition, because recent studies identified oRG-like progenitors in mice and marmosets, these animals also seem useful for examining the development of oRG cells (Garcia-Moreno et al., 2012; Kelava et al., 2011; Shitamukai et al., 2011; Wang et al., 2011). The identification of molecules whose expression patterns correspond to brain structures unique to carnivores and primates would facilitate our understanding of the development, function, pathophysiology and evolution of the brain. In addition, because a recent report uncovered four distinct morphologies of oRG cells in macaque (Betizeau et al., 2013), it would be intriguing to express GFP in oRG cells and examine the morphological diversity of oRG cells in ferrets.

Neuronal migration has also been examined using the cerebral cortex of ferrets (Anderson et al., 2002; Borrell et al., 2006; O'Rourke et al., 1997; O'Rourke et al., 1992; O'Rourke et al., 1995). Time-lapse confocal microscopy using cultured cortical slices showed that the majority of cells migrated along radial fibers, whereas a fraction of cells migrated orthogonal to the radial fibers (O'Rourke et al., 1992). After in vivo DiI focal injection, labeled cells migrated in all directions and over long distances (O'Rourke et al., 1997). These results suggest that cortical cells migrate not only radially but also non-radially, which may result in tangential dispersion. 


\section{The ferret as a model animal for investigating the visual cortex}

Using the developed visual system of carnivores and primates, key concepts related to the intrinsic and extrinsic factors responsible for brain development have been intensively investigated (Chalupa and Werner, 2003). For example, anatomical and molecular properties of ocular dominance columns (ODCs) and retinogeniculate projections, physiological descriptions of visual cortical responses, and the dendritic morphology of neurons have been uncovered (Callaway and Katz, 1993; Crowley and Katz, 1999, 2000; Horch and Katz, 2002; Huberman et al., 2005; Iwai et al., 2013; Kawasaki et al., 2004; Matsui et al., 2013; Usrey et al., 2003; Yu et al., 2005). Hubel and Wiesel initially uncovered ODCs in the primary visual cortex (V1) of cats in the early 1960s (Figure 2) (Hubel and Wiesel, 1962). Cortical neurons in V1 are activated differentially by the two eyes, and those cells with similar eye preference are grouped together into cortical columns in V1. This results from the segregation of left and right eye-specific lateral geniculate nucleus (LGN) axons into alternating stripes in cortical layer 4 of V1 (Figure 2). Notably, ODCs in V1 are observed in primates and carnivores including ferrets, but not in mice. ODCs can be revealed with electrophysiological techniques and trans-neuronal tracers such as tritiated amino acids. Although it has been assumed that ODCs are important in binocular vision, it is still unclear whether ODCs are functionally important or are just a byproduct.

ODCs in ferrets, cats and monkeys have been used for studying developmental plasticity. Monocular eye closure during the first few months of life - the critical period - decreased the number of neurons activated by the closed eye and increased the number of neurons activated by the intact open eye (Wiesel and Hubel, 1963, 1965a, b). The investigations of the effects of monocular eye closure suggested 
that pre-existing connections are substantially modified by an activity-dependent competitive process. Interestingly, visualization of geniculocortical axons by direct tracer injections into the LGN of early postnatal ferrets revealed segregated ODCs before the critical period (Crowley and Katz, 2000). These pioneering discoveries clearly distinguished between the innate mechanisms that guide the initial formation of cortical architecture and the experience-dependent, competition-based mechanisms responsible for their later modification during the critical period.

\section{The ferret as a model animal for investigating the retinogeniculate system}

The visual information detected by the retina is transferred to the LGN by the retinogeniculate projection. This retinogeniculate projection contains several distinct properties including eye specificity, ON/OFF responses and magnocellular/parvocellular/koniocellular (M/P/K) responses.

Using eye-specific projection in ferrets, the mechanisms underlying the activity-dependent development of connections have been investigated. In adult mammals, retinal ganglion cell (RGC) axons from the two eyes are segregated into eye-specific regions in the LGN (Figure 3). However, when retinogeniculate projections are initially formed early in development, RGC axons from the two eyes are intermingled in the LGN (Figure 3). After this initial formation, the refinement of RGC axons proceeds to make distinct eye-specific regions during development before vision occurs (eye-specific segregation). Eye-specific segregation requires spontaneous retinal activity called retinal waves, as monocular blockade of retinal waves prevents eye-specific segregation in the LGN (Penn et al., 1998). Projection from the intact retina is greatly expanded, whereas that from the inhibited retina is substantially reduced. 
These results suggest that spontaneous activity can produce highly stereotyped patterns of projections prior to visual experience (Huberman et al., 2003; Penn et al., 1998). It is believed that the firing patterns of retinal waves provide the appropriate spatial and temporal properties to guide the refinement of retinogeniculate projections (Meister et al., 1991). Retinal waves are seen during the same period as eye-specific segregation in the LGN and subside gradually as the connectivity of retinogeniculate projections stabilizes (Wong et al., 1993). Because, in addition to ferrets, mice also have eye-specific projections, mice are becoming much more popular for examining the mechanisms of eye-specific segregation during development (Chen and Regehr, 2000; Demas et al., 2006; Hayakawa and Kawasaki, 2010; Iwai and Kawasaki, 2009; Upton et al., 1999).

In contrast to eye-specific projections, the ON/OFF pathways and the $\mathrm{M} / \mathrm{P} / \mathrm{K}$ pathways are much more prominent in the retinogeniculate projections in ferrets than in mice. For example, ON cells and OFF cells are spatially intermingled in the mouse LGN whereas they are segregated into ON and OFF sublaminae in the ferret LGN (Stryker and Zahs, 1983). Using these ON and OFF sublaminae, the mechanisms underlying the formation of ON/OFF segregation in the ferret LGN have been examined. Pharmacological experiments showed that NMDA receptors are involved in ON/OFF segregation (Hahm et al., 1991). Downstream mediators of the NMDA receptor signaling seem to be nitric oxide (NO) and soluble guanylyl cyclase (sGC), because ON/OFF segregation was inhibited by the NO synthase inhibitor L-NoArg and ODQ, a specific inhibitor of sGC (Cramer et al., 1996; Leamey et al., 2001). It is likely that calcium influx through NMDA receptors activates NO synthase, resulting in activation of sGC during ON/OFF segregation in the LGN during development. It would be 
important to investigate whether NO and sGC work presynaptically or postsynaptically. It should be noted that NMDA receptors are crucial for the ON/OFF segregation of retinogeniculate axons, while they are irrelevant to the eye-specific segregation of retinogeniculate axons in the ferret LGN (Smetters et al., 1994). There seem to be distinct mechanisms underlying different types of segregation of retinogeniculate axons in the ferret LGN.

\section{The ferret as a model animal for investigating the parallel visual pathways}

The magnocellular/parvocellular/koniocellular parallel visual pathways are also more developed in higher mammals than in mice. Visual information detected by the retina is conveyed to V1 via the LGN along parallel visual pathways. The parallel visual pathways are composed of three pathways with distinct anatomical and physiological characteristics. The three pathways are known as the $\mathrm{X}, \mathrm{Y}$, and $\mathrm{W}$ pathways in carnivores and are also known as the parvocellular (P), magnocellular (M), and koniocellular (K) pathways in primates (DeYoe and Van Essen, 1988; Felleman and Van Essen, 1991; Hendry and Reid, 2000; Jones, 2007; Livingstone and Hubel, 1987; Maunsell, 1992; Nassi and Callaway, 2009; Sherman and Guillery, 2004; Sherman and Spear, 1982; Wassle, 2004). It has been proposed that these parallel visual pathways make different contributions to visual perception. The visual capabilities of monkeys were examined after selectively damaging either the M or P layers of the LGN. Damage to the M layers has little effect on visual acuity or color vision, but markedly reduces the ability to recognize moving stimuli. In contrast, damage to the P layers does not show apparent effects on motion perception but strongly impairs visual acuity and color perception. Thus, the visual information conveyed by the P pathway is important for the 
detailed analysis of the shape, size, and color of objects, whereas the M pathway is mainly concerned with information about the movement of objects.

In order to investigate the developed brain structures unique to higher mammals, it is important to identify molecules whose expression patterns correspond to these structures. Several groups including us have identified such molecules using carnivores and primates (Bernard et al., 2012; Iwai et al., 2013; Johnson et al., 2009; Kawasaki et al., 2004; Mashiko et al., 2012; Murray et al., 2008; Yamamori, 2011). Recently, we uncovered that the Forkhead transcription factor FoxP2 is selectively expressed in $\mathrm{X}$ cells of the adult ferret dLGN and in the P layers of the adult monkey LGN (Iwai et al., 2013). There is a longstanding question about the relationship between $\mathrm{M}$ and $\mathrm{P}$ cells in primates and $\mathrm{Y}$ and $\mathrm{X}$ cells in carnivores. It has been suggested that $\mathrm{X}$ and $\mathrm{Y}$ cells in carnivores are comparable with $\mathrm{P}$ and $\mathrm{M}$ cells in primates, respectively, while an alternative view is that $\mathrm{X}$ and $\mathrm{Y}$ cells are homologous to linear and non-linear $\mathrm{M}$ cells, respectively, and that $\mathrm{P}$ cells are unique to primates (Kaplan, 2004). Our findings that FoxP2 is selectively expressed in X cells in the ferret LGN and the P layers in the monkey LGN provide new evidence for a homology between X cells of ferrets and P cells of monkeys (Iwai et al., 2013). It would be intriguing to examine the role of FoxP2 in the development of $\mathrm{X}$ cells in carnivores and the P layers in primates because the molecular mechanisms underlying the formation of the parallel visual pathways during development are still unknown. Clinical investigation of the KE family, whose members have a mutated FOXP2 gene, would be informative. Another application of FoxP2 would be the characterization of the FoxP2 promoter, which may enable us to express genes of interest in the P pathway in the LGN selectively. A deeper understanding of the parallel visual pathways will provide not only 
information about visual recognition but will also contribute to our understanding of the evolution of the visual system and the general mechanisms by which the brain integrates information from multiple sources to create a unified, coherent percept of the external world.

\section{Other studies using the ferret as a model animal}

Rewiring of axonal projections was also revealed using the visual system of ferrets. (Angelucci et al., 1997; Roe et al., 1993; Roe et al., 1992; Sur et al., 1988). Following neonatal surgical manipulations, retinogeniculate axons can be induced to innervate the auditory thalamus (Sur et al., 1988). Importantly, visual responses can be recorded in the primary auditory cortex (Sur et al., 1988). Like cells in the normal primary visual cortex, cells in the primary auditory cortex of rewired animals exhibit orientation and direction selectivity and have simple and complex receptive field organizations (Roe et al., 1992). Among the three types of retinal ganglion cells (X, Y and $\mathrm{W}$ cells) of ferrets, W cells are mainly responsible for this rewiring (Roe et al., 1993). Interestingly, the eye-specific projection pattern in the LGN, which is one of the typical selective projection patterns in the visual system as discussed above, is recapitulated in the auditory thalamus of rewired ferrets (Angelucci et al., 1997). These results suggest that functional circuits are reconstituted in the auditory thalamus of rewired ferrets.

\section{Genetic manipulation of ferrets using in utero electroporation}

Although the creation of transgenic marmosets provided a new animal model for human disease (Okano et al., 2012), it was desirable to establish much more rapid and simple genetic manipulation methods for carnivores and primates. In utero electroporation is 
well known to be a useful technique to express genes of interest in the living rodent brain (Ako et al., 2011; Fukuchi-Shimogori and Grove, 2001; Saito and Nakatsuji, 2001; Sehara et al., 2010; Tabata and Nakajima, 2001). Because successful application of in utero electroporation in carnivores and primates had not been achieved, we recently developed and validated a rapid and efficient procedure for in utero electroporation for ferrets (Figure 4) (Kawasaki et al., 2012; Kawasaki et al., 2013). Using our procedure, transgene-expressing ferret babies can be obtained within a couple of days after electroporation. Expression of transgenes is detectable in the embryo and is observed as long as at least 2 months after birth. Transgenes can be expressed in both superficial and deep cortical neurons, depending on when electroporation is performed. Electroporation is performed at E31 and E37 to express transgenes in superficial and deep cortical neurons, respectively. Our method allows for the transfection of not only post-mitotic neurons but also neural progenitors, which include radial glial cells in the ventricular zone, outer radial glial cells in the OSVZ, and intermediate progenitor cells (Kawasaki et al., 2012; Kawasaki et al., 2013). Because the OSVZ in the developing cerebral cortex is especially prominent in gyrencephalic mammals, it would be intriguing to examine the mechanisms of OSVZ formation and the roles of the OSVZ in the formation of the gyrencephalic cortex.

In utero electroporation is useful not only for investigating molecular mechanisms but also for uncovering novel neuronal circuitry (Sehara et al., 2010; Sehara et al., 2012). Corticogenesis in monkeys and humans is distinguished by the appearance of the inner fiber layer (IFL), a thin layer of fibers located between the ISVZ and the OSVZ in the developmental cortex (Smart et al., 2002; Zecevic et al., 2005). However, a previous study using ferrets failed to find an obvious fiber layer 
corresponding to the IFL of primates (Martinez-Cerdeno et al., 2012), and it was unclear from which neurons the IFL is derived (Molnar and Clowry, 2012). Interestingly, when we expressed GFP in layer 2/3 neurons in the ferret cerebral cortex using in utero electroporation, GFP-positive fibers were observed in the inner OSVZ, suggesting that ferrets do have the fiber layer corresponding to the IFL in primates (Kawasaki et al., 2013). This result also suggests that the IFL is derived from cortical layer $2 / 3$ neurons, at least partially (Kawasaki et al., 2013). One intriguing hypothesis would be that an increase in the number of layer 2/3 neurons during evolution resulted in the formation of the thick bundle of the IFL.

In utero electroporation has several important features. First, it is easy to express multiple genes simultaneously. When a mixture of GFP and mCherry expression plasmids is used, most GFP-positive neurons are also positive for mCherry, suggesting that co-transfection efficiencies are reasonably high. Second, transgenes can be expressed in selected brain regions by adjusting the direction of electrodes and the age at which electroporation is performed. Because of the results obtained using rodents (Borrell et al., 2005; Garcia-Frigola et al., 2007; Hatanaka et al., 2004; Kataoka and Shimogori, 2008; Nakahira and Yuasa, 2005; Soma et al., 2009), it seems reasonable to speculate that genetic manipulation using in utero electroporation can be applied to other brain regions such as the hippocampus, the thalamus, the retina and the amygdala in ferrets. Third, because larger plasmids can be introduced using electroporation, combining electroporation and cell-type specific promoters would be valuable to regulate the distribution patterns of transgenes. For example, the Thy1S promoter seems useful for labeling neurons sparsely (Ako et al., 2011). Finally, it takes relatively little time and effort to express genes of interest using in utero electroporation. It takes only a 
couple of days to make transfected ferrets. Because in utero electroporation is applicable not only to rodents but also to carnivores, it could be also used in other higher mammals such as primates.

In addition to in utero electroporation, it was reported that postnatal electroporation was also a feasible method for expressing genes into the cerebral cortex of ferrets (Borrell, 2010). However, gene expression using postnatal electroporation is mostly observed in superficial layer $2 / 3$ in the ferret cerebral cortex. The reason for this seems to be that most cortical neurons had already moved into the cortical plate from the ventricular zone when postnatal electroporation was carried out. Combining postnatal and in utero electroporation, most of the cortical layers of ferrets can be manipulated.

In addition, it seems useful to compare the properties of ferrets with those of marmosets. About 8 babies are often born from one pregnant ferret mother, whereas 1-2 are born from a pregnant marmoset. This large number of babies per one pregnant mother is an important advantage of using ferrets, and it is helpful for obtaining a sufficient number of experimental samples. In addition, the gestation period of ferrets is shorter than that of marmosets (ferrets, 42 days; marmosets, 150 days). Ferrets and marmosets become sexually mature at about 8 months old and 14 months old, respectively, and the average life span is 5-10 years in ferrets and 10-15 years in marmosets. Therefore, the ferret is an interesting option for exploring developed brain structures.

\section{Conclusions}

In this article, mainly focusing on ferrets, I have summarized recent advances in 
molecular investigations of the brain of higher mammals. Given that one of the ultimate goals of neuroscience research is to understand the human brain, molecular investigations of the brain of carnivores and primates are of great importance. Because a rapid and simple genetic manipulation is now feasible using ferrets, the ferret is an important option for neuroscience researchers.

\section{Acknowledgments}

I apologize to numerous authors whose valuable papers I was not able to cite due to space limitations. I am grateful to Drs. Shoji Tsuji (The University of Tokyo), Haruhiko Bito (The University of Tokyo), Eisuke Nishida (Kyoto University), Yoshiki Sasai (RIKEN-CDB) and Shigetada Nakanishi (Osaka Bioscience Institute) for their continuous encouragement and warm support. I thank Kawasaki lab members for their help. This work was supported by Grant-in-Aid for Scientific Research from MEXT, Takeda Science Foundation, Takeda Medical Research Foundation, Astellas Foundation for Research on Metabolic Disorders, the Kurata Memorial Hitachi Science and Technology Foundation, Mitsubishi Foundation, and Research Foundation for Opto-Science and Technology. 


\section{Figure Legends}

Figure 1. The cerebral cortex of ferrets at P18. Note that cortical gyri are clearly visible.

Figure 2. Schematic organization of ocular dominance columns in the primary visual cortex (V1). Note that cortical neurons in different ODCs of V1 are activated preferentially by one of the two eyes. LGN, lateral geniculate nucleus; ODC, ocular dominance column; V1, primary visual cortex.

Figure 3. Eye-specific segregation of retinogeniculate projections in the LGN. RGC axons from the two eyes are initially intermingled in the LGN (left) and then are segregated into eye-specific regions (right) during development.

Figure 4. GFP expression in the ferret brain induced by in utero electroporation. An example of the ferret brain that was electroporated at E32 and examined at P17. 


\section{References}

Ako, R., Wakimoto, M., Ebisu, H., Tanno, K., Hira, R., Kasai, H., Matsuzaki, M., Kawasaki, H., 2011. Simultaneous visualization of multiple neuronal properties with single-cell resolution in the living rodent brain. Mol. Cell. Neurosci. 48, 246-257.

Anderson, S.A., Kaznowski, C.E., Horn, C., Rubenstein, J.L., McConnell, S.K., 2002. Distinct origins of neocortical projection neurons and interneurons in vivo. Cereb. Cortex 12, 702-709.

Angelucci, A., Clasca, F., Bricolo, E., Cramer, K.S., Sur, M., 1997. Experimentally induced retinal projections to the ferret auditory thalamus: development of clustered eye-specific patterns in a novel target. J. Neurosci. 17, 2040-2055.

Ayoub, A.E., Oh, S., Xie, Y., Leng, J., Cotney, J., Dominguez, M.H., Noonan, J.P., Rakic, P., 2011. Transcriptional programs in transient embryonic zones of the cerebral cortex defined by high-resolution mRNA sequencing. Proc. Natl. Acad. Sci. USA 108, 14950-14955.

Bernard, A., Lubbers, L.S., Tanis, K.Q., Luo, R., Podtelezhnikov, A.A., Finney, E.M., McWhorter, M.M.E., Serikawa, K., Lemon, T., Morgan, R., Copeland, C., Smith, K., Cullen, V., Davis-Turak, J., Lee, C.-K., Sunkin, S.M., Loboda, A.P., Levine, D.M., Stone, D.J., Hawrylycz, M.J., Roberts, C.J., Jones, A.R., Geschwind, D.H., Lein, E.S., 2012. Transcriptional architecture of the primate neocortex. Neuron 73, 1083-1099.

Betizeau, M., Cortay, V., Patti, D., Pfister, S., Gautier, E., Bellemin-Menard, A., Afanassieff, M., Huissoud, C., Douglas, R.J., Kennedy, H., Dehay, C., 2013. Precursor diversity and complexity of lineage relationships in the outer subventricular zone of the primate. Neuron 80, 442-457.

Borrell, V., 2010. In vivo gene delivery to the postnatal ferret cerebral cortex by DNA electroporation. J. Neurosci. Methods 186, 186-195.

Borrell, V., Kaspar, B.K., Gage, F.H., Callaway, E.M., 2006. In vivo evidence for radial migration of neurons by long-distance somal translocation in the developing ferret 
visual cortex. Cereb. Cortex 16, 1571-1583.

Borrell, V., Reillo, I., 2012. Emerging roles of neural stem cells in cerebral cortex development and evolution. Dev. Neurobiol. 72, 955-971.

Borrell, V., Yoshimura, Y., Callaway, E.M., 2005. Targeted gene delivery to telencephalic inhibitory neurons by directional in utero electroporation. J. Neurosci. Methods 143, 151-158.

Callaway, E.M., Katz, L.C., 1993. Photostimulation using caged glutamate reveals functional circuitry in living brain slices. Proc. Natl. Acad. Sci. USA 90, 7661-7665.

Chalupa, L.M., Werner, J.S., 2003. The Visual Neuroscience. The MIT Press, Cambridge.

Chan, A.W., Chong, K.Y., Martinovich, C., Simerly, C., Schatten, G., 2001. Transgenic monkeys produced by retroviral gene transfer into mature oocytes. Science 291, 309-312.

Chen, C., Regehr, W.G., 2000. Developmental remodeling of the retinogeniculate synapse. Neuron 28, 955-966.

Cramer, K.S., Angelucci, A., Hahm, J.O., Bogdanov, M.B., Sur, M., 1996. A role for nitric oxide in the development of the ferret retinogeniculate projection. J. Neurosci. 16, 7995-8004.

Crowley, J.C., Katz, L.C., 1999. Development of ocular dominance columns in the absence of retinal input. Nat. Neurosci. 2, 1125-1130.

Crowley, J.C., Katz, L.C., 2000. Early development of ocular dominance columns. Science 290, 1321-1324.

Dehay, C., Kennedy, H., 2007. Cell-cycle control and cortical development. Nat. Rev. Neurosci. 8, 438-450.

Demas, J., Sagdullaev, B.T., Green, E., Jaubert-Miazza, L., McCall, M.A., Gregg, R.G., Wong, R.O., Guido, W., 2006. Failure to maintain eye-specific segregation in nob, a 
mutant with abnormally patterned retinal activity. Neuron 50, 247-259.

DeYoe, E.A., Van Essen, D.C., 1988. Concurrent processing streams in monkey visual cortex. Trends Neurosci. 11, 219-226.

Felleman, D.J., Van Essen, D.C., 1991. Distributed hierarchical processing in the primate cerebral cortex. Cereb. Cortex 1, 1-47.

Fietz, S.A., Huttner, W.B., 2011. Cortical progenitor expansion, self-renewal and neurogenesis-a polarized perspective. Curr. Opin. Neurobiol. 21, 23-35.

Fietz, S.A., Kelava, I., Vogt, J., Wilsch-Brauninger, M., Stenzel, D., Fish, J.L., Corbeil, D., Riehn, A., Distler, W., Nitsch, R., Huttner, W.B., 2010. OSVZ progenitors of human and ferret neocortex are epithelial-like and expand by integrin signaling. Nat. Neurosci. 13, 690-699.

Fukuchi-Shimogori, T., Grove, E.A., 2001. Neocortex patterning by the secreted signaling molecule FGF8. Science 294, 1071-1074.

Garcia-Frigola, C., Carreres, M.I., Vegar, C., Herrera, E., 2007. Gene delivery into mouse retinal ganglion cells by in utero electroporation. BMC Dev. Biol. 7, 103.

Garcia-Moreno, F., Vasistha, N.A., Trevia, N., Bourne, J.A., Molnar, Z., 2012. Compartmentalization of cerebral cortical germinal zones in a lissencephalic primate and gyrencephalic rodent. Cereb. Cortex 22, 482-492.

Hahm, J.O., Langdon, R.B., Sur, M., 1991. Disruption of retinogeniculate afferent segregation by antagonists to NMDA receptors. Nature 351, 568-570.

Hansen, D.V., Lui, J.H., Parker, P.R., Kriegstein, A.R., 2010. Neurogenic radial glia in the outer subventricular zone of human neocortex. Nature 464, 554-561.

Hatanaka, Y., Hisanaga, S., Heizmann, C.W., Murakami, F., 2004. Distinct migratory behavior of early- and late-born neurons derived from the cortical ventricular zone. J. Comp. Neurol. 479, 1-14.

Haubensak, W., Attardo, A., Denk, W., Huttner, W.B., 2004. Neurons arise in the basal 
neuroepithelium of the early mammalian telencephalon: a major site of neurogenesis. Proc. Natl. Acad. Sci. USA 101, 3196-3201.

Hayakawa, I., Kawasaki, H., 2010. Rearrangement of retinogeniculate projection patterns after eye-specific segregation in mice. PLoS One 5, e11001.

Hendry, S.H., Reid, R.C., 2000. The koniocellular pathway in primate vision. Annu. Rev. Neurosci. 23, 127-153.

Hevner, R.F., Haydar, T.F., 2012. The (not necessarily) convoluted role of basal radial glia in cortical neurogenesis. Cereb. Cortex 22, 465-468.

Horch, H.W., Katz, L.C., 2002. BDNF release from single cells elicits local dendritic growth in nearby neurons. Nat. Neurosci. 5, 1177-1184.

Hubel, D.H., Wiesel, T.N., 1962. Receptive fields, binocular interaction and functional architecture in the cat's visual cortex. J. Physiol. 160, 106-154.

Huberman, A.D., Murray, K.D., Warland, D.K., Feldheim, D.A., Chapman, B., 2005. Ephrin-As mediate targeting of eye-specific projections to the lateral geniculate nucleus. Nat. Neurosci. 8, 1013-1021.

Huberman, A.D., Wang, G.Y., Liets, L.C., Collins, O.A., Chapman, B., Chalupa, L.M., 2003. Eye-specific retinogeniculate segregation independent of normal neuronal activity. Science 300, 994-998.

Iwai, L., Kawasaki, H., 2009. Molecular development of the lateral geniculate nucleus in the absence of retinal waves during the time of retinal axon eye-specific segregation. Neuroscience 159, 1326-1337.

Iwai, L., Ohashi, Y., van der List, D., Usrey, W.M., Miyashita, Y., Kawasaki, H., 2013. FoxP2 is a parvocellular-specific transcription factor in the visual thalamus of monkeys and ferrets. Cereb. Cortex 23, 2204-2212.

Johnson, M.B., Kawasawa, Y.I., Mason, C.E., Krsnik, Z., Coppola, G., Bogdanovic, D., Geschwind, D.H., Mane, S.M., State, M.W., Sestan, N., 2009. Functional and evolutionary insights into human brain development through global transcriptome 
analysis. Neuron 62, 494-509.

Jones, E.G., 2007. The thalamus, 2nd ed. Cambridge University Press, Cambridge.

Kaplan, E., 2004. The M, P, and K pathways of the primate visual system, In: Chalupa, L.M., Werner, J.S. (Eds.), The Visual Neurosciences. 1 vol. MIT Press, Cambridge, pp. 481-493.

Kataoka, A., Shimogori, T., 2008. Fgf8 controls regional identity in the developing thalamus. Development 135, 2873-2881.

Kawasaki, H., Crowley, J.C., Livesey, F.J., Katz, L.C., 2004. Molecular organization of the ferret visual thalamus. J. Neurosci. 24, 9962-9970.

Kawasaki, H., Iwai, L., Tanno, K., 2012. Rapid and efficient genetic manipulation of gyrencephalic carnivores using in utero electroporation. Mol. Brain 5, 24.

Kawasaki, H., Toda, T., Tanno, K., 2013. In vivo genetic manipulation of cortical progenitors in gyrencephalic carnivores using in utero electroporation. Biol. Open 2, 95-100.

Kelava, I., Reillo, I., Murayama, A.Y., Kalinka, A.T., Stenzel, D., Tomancak, P., Matsuzaki, F., Lebrand, C., Sasaki, E., Schwamborn, J.C., Okano, H., Huttner, W.B., Borrell, V., 2011. Abundant occurrence of basal radial glia in the subventricular zone of embryonic neocortex of a lissencephalic primate, the common marmoset Callithrix jacchus. Cereb. Cortex 22, 469-481.

Leamey, C.A., Ho-Pao, C.L., Sur, M., 2001. Disruption of retinogeniculate pattern formation by inhibition of soluble guanylyl cyclase. J. Neurosci. 21, 3871-3880.

Livingstone, M.S., Hubel, D.H., 1987. Psychophysical evidence for separate channels for the perception of form, color, movement, and depth. J. Neurosci. 7, 3416-3468.

Lois, C., Hong, E.J., Pease, S., Brown, E.J., Baltimore, D., 2002. Germline transmission and tissue-specific expression of transgenes delivered by lentiviral vectors. Science 295, 868-872. 
Lui, J.H., Hansen, D.V., Kriegstein, A.R., 2011. Development and evolution of the human neocortex. Cell 146, 18-36.

Malatesta, P., Hartfuss, E., Gotz, M., 2000. Isolation of radial glial cells by fluorescent-activated cell sorting reveals a neuronal lineage. Development 127, 5253-5263.

Martinez-Cerdeno, V., Cunningham, C.L., Camacho, J., Antczak, J.L., Prakash, A.N., Cziep, M.E., Walker, A.I., Noctor, S.C., 2012. Comparative analysis of the subventricular zone in rat, ferret and macaque: evidence for an outer subventricular zone in rodents. PLoS One 7, e30178.

Mashiko, H., Yoshida, A.C., Kikuchi, S.S., Niimi, K., Takahashi, E., Aruga, J., Okano, H., Shimogori, T., 2012. Comparative anatomy of marmoset and mouse cortex from genomic expression. J. Neurosci. 32, 5039-5053.

Matsui, A., Tran, M., Yoshida, A.C., Kikuchi, S.S., U, M., Ogawa, M., Shimogori, T., 2013. BTBD3 controls dendrite orientation toward active axons in mammalian neocortex. Science 342, 1114-1118.

Maunsell, J.H., 1992. Functional visual streams. Curr. Opin. Neurobiol. 2, 506-510.

Meister, M., Wong, R.O., Baylor, D.A., Shatz, C.J., 1991. Synchronous bursts of action potentials in ganglion cells of the developing mammalian retina. Science 252, 939-943.

Miyata, T., Kawaguchi, A., Okano, H., Ogawa, M., 2001. Asymmetric inheritance of radial glial fibers by cortical neurons. Neuron 31, 727-741.

Molnar, Z., Clowry, G., 2012. Cerebral cortical development in rodents and primates. Prog. Brain Res. 195, 45-70.

Murray, K.D., Rubin, C.M., Jones, E.G., Chalupa, L.M., 2008. Molecular correlates of laminar differences in the macaque dorsal lateral geniculate nucleus. J. Neurosci. 28, 12010-12022.

Nakahira, E., Yuasa, S., 2005. Neuronal generation, migration, and differentiation in the mouse hippocampal primoridium as revealed by enhanced green fluorescent protein 
gene transfer by means of in utero electroporation. J. Comp. Neurol. 483, 329-340.

Nassi, J.J., Callaway, E.M., 2009. Parallel processing strategies of the primate visual system. Nat. Rev. Neurosci. 10, 360-372.

Noctor, S.C., Flint, A.C., Weissman, T.A., Dammerman, R.S., Kriegstein, A.R., 2001. Neurons derived from radial glial cells establish radial units in neocortex. Nature 409, 714-720.

Noctor, S.C., Martinez-Cerdeno, V., Ivic, L., Kriegstein, A.R., 2004. Cortical neurons arise in symmetric and asymmetric division zones and migrate through specific phases. Nat. Neurosci. 7, 136-144.

Nonaka-Kinoshita, M., Reillo, I., Artegiani, B., Martinez-Martinez, M.A., Nelson, M., Borrell, V., Calegari, F., 2013. Regulation of cerebral cortex size and folding by expansion of basal progenitors. EMBO J. 32, 1817-1828.

O'Rourke, N.A., Chenn, A., McConnell, S.K., 1997. Postmitotic neurons migrate tangentially in the cortical ventricular zone. Development 124, 997-1005.

O'Rourke, N.A., Dailey, M.E., Smith, S.J., McConnell, S.K., 1992. Diverse migratory pathways in the developing cerebral cortex. Science 258, 299-302.

O'Rourke, N.A., Sullivan, D.P., Kaznowski, C.E., Jacobs, A.A., McConnell, S.K., 1995. Tangential migration of neurons in the developing cerebral cortex. Development 121, 2165-2176.

Okano, H., Hikishima, K., Iriki, A., Sasaki, E., 2012. The common marmoset as a novel animal model system for biomedical and neuroscience research applications. Semin. Fetal. Neonatal. Med. 17, 336-340.

Penn, A.A., Riquelme, P.A., Feller, M.B., Shatz, C.J., 1998. Competition in retinogeniculate patterning driven by spontaneous activity. Science 279, 2108-2112.

Pilz, G.A., Shitamukai, A., Reillo, I., Pacary, E., Schwausch, J., Stahl, R., Ninkovic, J., Snippert, H.J., Clevers, H., Godinho, L., Guillemot, F., Borrell, V., Matsuzaki, F., Gotz, M., 2013. Amplification of progenitors in the mammalian telencephalon includes a new 
radial glial cell type. Nat. Commun. 4, 2125.

Rakic, P., 2009. Evolution of the neocortex: a perspective from developmental biology. Nat. Rev. Neurosci. 10, 724-735.

Reillo, I., de Juan Romero, C., Garcia-Cabezas, M.A., Borrell, V., 2011. A role for intermediate radial glia in the tangential expansion of the mammalian cerebral cortex. Cereb. Cortex 21, 1674-1694.

Roe, A.W., Garraghty, P.E., Esguerra, M., Sur, M., 1993. Experimentally induced visual projections to the auditory thalamus in ferrets: evidence for a W cell pathway. J. Comp. Neurol. 334, 263-280.

Roe, A.W., Pallas, S.L., Kwon, Y.H., Sur, M., 1992. Visual projections routed to the auditory pathway in ferrets: receptive fields of visual neurons in primary auditory cortex. J. Neurosci. 12, 3651-3664.

Saito, T., Nakatsuji, N., 2001. Efficient gene transfer into the embryonic mouse brain using in vivo electroporation. Dev. Biol. 240, 237-246.

Sasaki, E., Suemizu, H., Shimada, A., Hanazawa, K., Oiwa, R., Kamioka, M., Tomioka, I., Sotomaru, Y., Hirakawa, R., Eto, T., Shiozawa, S., Maeda, T., Ito, M., Ito, R., Kito, C., Yagihashi, C., Kawai, K., Miyoshi, H., Tanioka, Y., Tamaoki, N., Habu, S., Okano, H., Nomura, T., 2009. Generation of transgenic non-human primates with germline transmission. Nature 459, 523-527.

Sehara, K., Toda, T., Iwai, L., Wakimoto, M., Tanno, K., Matsubayashi, Y., Kawasaki, H., 2010. Whisker-related axonal patterns and plasticity of layer 2/3 neurons in the mouse barrel cortex. J. Neurosci. 30, 3082-3092.

Sehara, K., Wakimoto, M., Ako, R., Kawasaki, H., 2012. Distinct developmental principles underlie the formation of ipsilateral and contralateral whisker-related axonal patterns of layer 2/3 neurons in the barrel cortex. Neuroscience 226, 289-304.

Sherman, S.M., Guillery, R.W., 2004. Thalamus, In: Shepherd, G.M. (Ed.), The synaptic organization of the brain, 5th ed. Oxford University Press, New York, pp. 311-359. 
Sherman, S.M., Spear, P.D., 1982. Organization of visual pathways in normal and visually deprived cats. Physiol. Rev. 62, 738-855.

Shitamukai, A., Konno, D., Matsuzaki, F., 2011. Oblique radial glial divisions in the developing mouse neocortex induce self-renewing progenitors outside the germinal zone that resemble primate outer subventricular zone progenitors. J. Neurosci. 31, 3683-3695.

Smart, I.H., Dehay, C., Giroud, P., Berland, M., Kennedy, H., 2002. Unique morphological features of the proliferative zones and postmitotic compartments of the neural epithelium giving rise to striate and extrastriate cortex in the monkey. Cereb. Cortex 12, 37-53.

Smetters, D.K., Hahm, J., Sur, M., 1994. An N-methyl-D-aspartate receptor antagonist does not prevent eye-specific segregation in the ferret retinogeniculate pathway. Brain Res. 658, 168-178.

Soma, M., Aizawa, H., Ito, Y., Maekawa, M., Osumi, N., Nakahira, E., Okamoto, H., Tanaka, K., Yuasa, S., 2009. Development of the mouse amygdala as revealed by enhanced green fluorescent protein gene transfer by means of in utero electroporation. $\mathrm{J}$. Comp. Neurol. 513, 113-128.

Stryker, M.P., Zahs, K.R., 1983. On and off sublaminae in the lateral geniculate nucleus of the ferret. J. Neurosci. 3, 1943-1951.

Sur, M., Garraghty, P.E., Roe, A.W., 1988. Experimentally induced visual projections into auditory thalamus and cortex. Science 242, 1437-1441.

Tabata, H., Nakajima, K., 2001. Efficient in utero gene transfer system to the developing mouse brain using electroporation: visualization of neuronal migration in the developing cortex. Neuroscience 103, 865-872.

Upton, A.L., Salichon, N., Lebrand, C., Ravary, A., Blakely, R., Seif, I., Gaspar, P., 1999. Excess of serotonin (5-HT) alters the segregation of ispilateral and contralateral retinal projections in monoamine oxidase A knock-out mice: possible role of 5-HT uptake in retinal ganglion cells during development. J. Neurosci. 19, 7007-7024. 
Usrey, W.M., Sceniak, M.P., Chapman, B., 2003. Receptive fields and response properties of neurons in layer 4 of ferret visual cortex. J. Neurophysiol. 89, 1003-1015.

Wang, X., Tsai, J.W., LaMonica, B., Kriegstein, A.R., 2011. A new subtype of progenitor cell in the mouse embryonic neocortex. Nat. Neurosci. 14, 555-561.

Wassle, H., 2004. Parallel processing in the mammalian retina. Nat. Rev. Neurosci. 5, 747-757.

Wiesel, T.N., Hubel, D.H., 1963. Single-cell responses in striate cortex of kittens deprived of vision in one eye. J. Neurophysiol. 26, 1003-1017.

Wiesel, T.N., Hubel, D.H., 1965a. Comparison of the effects of unilateral and bilateral eye closure on cortical unit responses in kittens. J. Neurophysiol. 28, 1029-1040.

Wiesel, T.N., Hubel, D.H., 1965b. Extent of recovery from the effects of visual deprivation in kittens. J. Neurophysiol. 28, 1060-1072.

Wong, R.O., Meister, M., Shatz, C.J., 1993. Transient period of correlated bursting activity during development of the mammalian retina. Neuron 11, 923-938.

Yamamori, T., 2011. Selective gene expression in regions of primate neocortex: implications for cortical specialization. Prog. Neurobiol. 94, 201-222.

Yu, H., Farley, B.J., Jin, D.Z., Sur, M., 2005. The coordinated mapping of visual space and response features in visual cortex. Neuron 47, 267-280.

Zecevic, N., Chen, Y., Filipovic, R., 2005. Contributions of cortical subventricular zone to the development of the human cerebral cortex. J. Comp. Neurol. 491, 109-122. 


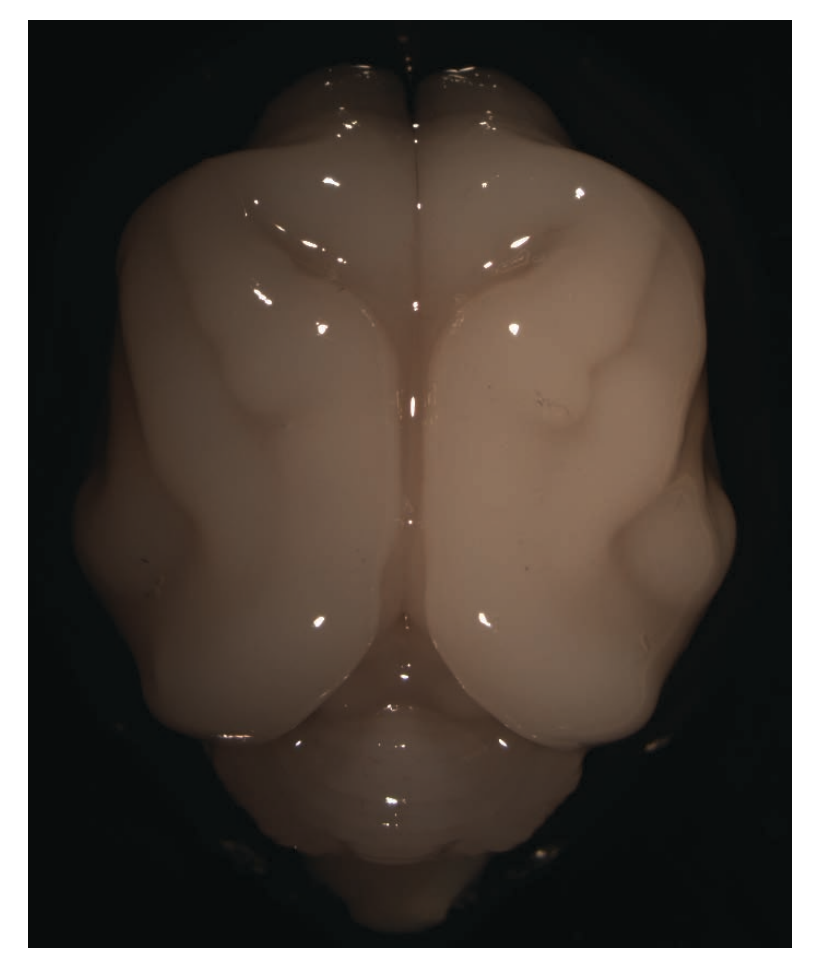

Figure 1 


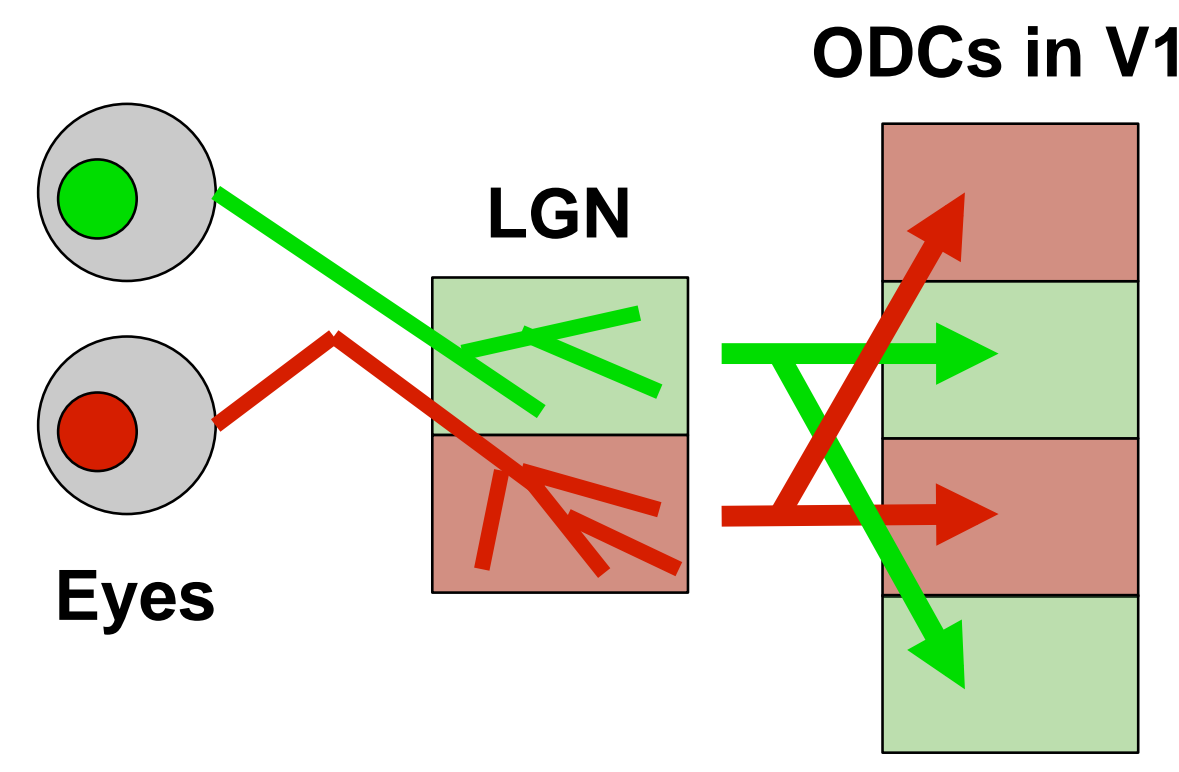

Figure 2 


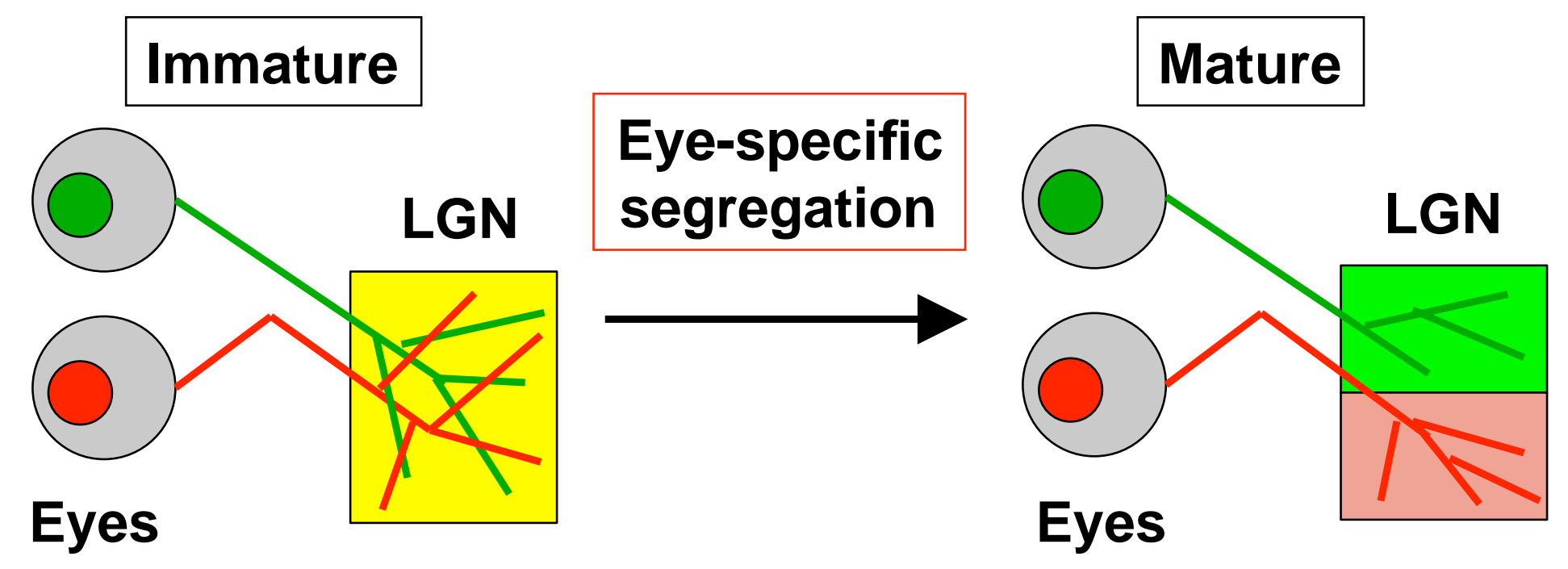

Figure 3 
GFP

\section{Bright field}

Figure 4 